\title{
Infections in Dupilumab Clinical Trials in Atopic Dermatitis: A Comprehensive Pooled Analysis
}

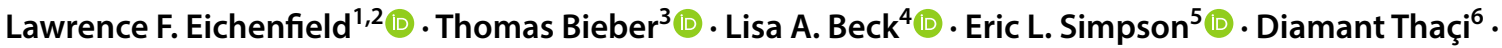

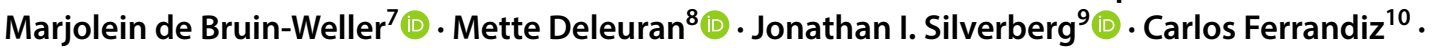 \\ Regina Fölster-Holst ${ }^{11} \cdot$ Zhen Chen $^{12}$. Neil M. H. Graham ${ }^{12}$. Gianluca Pirozzi ${ }^{13}$. Bolanle Akinlade ${ }^{12}$ (1) \\ George D. Yancopoulos ${ }^{12} \cdot$ Marius Ardeleanu $^{12}$ (1)
}

Published online: 7 May 2019

(c) The Author(s) 2019

\begin{abstract}
Background Patients with moderate-to-severe atopic dermatitis (AD) have increased infection risk, including skin infections and systemic infections. Immunomodulators (e.g., anti-tumor necrosis factors, anti-interleukin [anti-IL]-23, anti-IL-17, Janus kinase inhibitors) increase risk of infections. Dupilumab (a monoclonal antibody blocking the shared receptor component for IL-4 and IL-13) is approved for inadequately controlled moderate-to-severe AD and for moderate-to-severe eosinophilic or oral corticosteroid-dependent asthma.

Objective The aim was to determine the impact of dupilumab on infection rates in patients with moderate-to-severe AD.

Methods This analysis pooled data from seven randomized, placebo-controlled dupilumab trials in adults with moderateto-severe AD. Exposure-adjusted analyses assessed infection rates.

Results Of 2932 patients, 1091 received placebo, 1095 dupilumab $300 \mathrm{mg}$ weekly, and 746 dupilumab $300 \mathrm{mg}$ every 2 weeks. Treatment groups had similar infection rates overall per 100 patient-years (placebo, 155; dupilumab weekly, 150; dupilumab every 2 weeks, 156; dupilumab combined, 152), and similar non-skin infection rates. Serious/severe infections were reduced with dupilumab (risk ratio $0.43 ; p<0.05$ ), as were bacterial and other non-herpetic skin infections (risk ratio $0.44 ; p<0.001$ ). Although herpesviral infection rates overall were slightly higher with dupilumab than placebo, clinically important herpesviral infections (eczema herpeticum, herpes zoster) were less common with dupilumab (risk ratio 0.31; $p<0.01)$. Systemic anti-infective medication use was lower with dupilumab.

Conclusions Dupilumab is associated with reduced risk of serious/severe infections and non-herpetic skin infections and does not increase overall infection rates versus placebo in patients with moderate-to-severe AD.

ClinicalTrials.gov Identifiers NCT01548404, NCT02210780, NCT01859988, NCT02277743, NCT02277769, NCT02260986, and NCT02755649.
\end{abstract}

\section{Introduction}

Atopic dermatitis (AD) is a chronic pruritic inflammatory skin disease characterized by skin barrier dysfunction, including imbalance of the skin microbiome, and immune dysregulation primarily skewed toward type 2 activity [1,2]. Reduced expression of antimicrobial peptides and alterations

Electronic supplementary material The online version of this article (https://doi.org/10.1007/s40257-019-00445-7) contains supplementary material, which is available to authorized users.

Lawrence F. Eichenfield

Leichenfield@ rchsd.org

Extended author information available on the last page of the article in the skin microbiome, including Staphylococcus aureus colonization, contribute to AD pathobiology [3-5].

Patients with $\mathrm{AD}$ are at increased risk of serious bacterial skin infections and viral skin infections, including eczema herpeticum, eczema vaccinatum, and eczema coxsackium [5-17] and, compared with the general population, are at increased risk of serious extracutaneous and systemic infections [17-19].

Dupilumab, a fully human monoclonal antibody derived by proprietary technologies [20,21], blocks the shared receptor component for interleukin-4 (IL-4) and IL-13, thus inhibiting signaling of both IL-4 and IL-13. Dupilumab is approved for subcutaneous (SC) administration at $300 \mathrm{mg}$ every 2 weeks (q2w) for the treatment of patients 12 years and older in the USA with moderate-to-severe $\mathrm{AD}$ 


\section{Key Points}

We conducted a comprehensive analysis of pooled data from seven randomized, double-blinded, placebocontrolled clinical trials of dupilumab (with or without concomitant topical corticosteroids) in adults with atopic dermatitis.

Dupilumab treatment does not increase infection risk overall and is associated with lower rates of serious or severe infections and lower rates of non-herpetic skin infections, compared with placebo.

Rates of herpesviral infections are slightly higher with dupilumab, mostly those due to oral herpes, but clinically important herpesviral infections, such as herpes zoster and eczema herpeticum, are lower with dupilumab than placebo.

inadequately controlled with topical prescription therapies or when those therapies are not advisable [22], for the treatment of adult $\mathrm{AD}$ patients not adequately controlled with existing therapies in Japan [23], and for use in adults with inadequately controlled, moderate-to-severe $\mathrm{AD}$ who are candidates for systemic therapy in the European Union [24]. Dupilumab is also approved by the US Food and Drug Administration [22] as an add-on maintenance treatment in patients with moderate-to-severe asthma aged $\geq 12$ years with an eosinophilic phenotype or with oral corticosteroiddependent asthma, regardless of eosinophilic phenotype [25-27]. In addition, dupilumab treatment has significantly improved signs and symptoms and had an overall favorable safety profile in clinical trials in other type 2 immune diseases, including chronic rhinosinusitis with nasal polyposis (CRSwNP), and eosinophilic esophagitis, thus demonstrating the importance of IL- 4 and IL-13 as drivers of multiple type 2 atopic/allergic diseases [28, 29].

Immunomodulatory agents, such as anti-tumor necrosis factor (anti-TNF) agents, anti-IL-23, anti-IL-17, and Janus kinase (JAK) inhibitors, increase the risk of infections [30-46]. However, in clinical trials with dupilumab, there was no evidence of an increase in overall infection rates, nor was there evidence of increased risk of serious or opportunistic infections in dupilumab-treated patients [25-29, 47-53]. Moreover, in clinical trials of dupilumab in patients with moderate-to-severe $\mathrm{AD}$, dupilumab-treated patients have shown trends toward lower rates of bacterial and other non-herpetic skin infections and lower rates of the clinically important herpesviral infections eczema herpeticum and herpes zoster, but slightly higher rates of herpes simplex viral infections (i.e., non-eczema herpeticum or herpes zoster) compared with placebo [47-52].
Because pooling data from multiple clinical trials increases the likelihood of identifying and confirming signals from individual studies, we conducted a comprehensive analysis of pooled data from randomized, placebocontrolled, double-blinded, phase II and phase III clinical trials with treatment periods of 12-52 weeks to further evaluate the incidence of infections in studies of dupilumab in patients with $\mathrm{AD}$. The objective of this pooled analysis was to assess infection rates for two regimens of dupilumab (SC $300 \mathrm{mg}$ weekly [qw] or $300 \mathrm{mg} \mathrm{q} 2 \mathrm{w}$ ), compared with placebo, in adult patients with moderate-to-severe AD.

\section{Methods}

\subsection{Studies}

This pooled analysis included data from seven phase II and phase III randomized, placebo-controlled, doubleblinded studies of dupilumab in adults with moderate-tosevere AD (R668-AD-1117, LIBERTY AD EVALUATE, R668-AD-1021, LIBERTY AD SOLO 1, LIBERTY AD SOLO 2, LIBERTY AD CHRONOS, and LIBERTY AD CAFÉ) [47-52]. Detailed study designs are provided in the respective publications and are summarized in Table E1 in the Electronic Supplementary Material (ESM).

The analyses included all patients who received at least one dose of study drug (SC dupilumab $300 \mathrm{mg} \mathrm{qw}, 300 \mathrm{mg}$ $\mathrm{q} 2 \mathrm{w}$, or placebo). Patients were categorized in treatment groups based on the treatment received (safety analysis set).

\subsection{Endpoints}

The endpoints used in this study are described in Table E2 in the ESM and include infections overall, infections leading to permanent discontinuation of study drug, serious or severe infections, non-herpetic skin infections, non-skin infections, and herpesviral infections. The definitions of the endpoints are based on reports of treatment-emergent adverse events (TEAEs) made during the treatment period of the clinical trials and are described according to the system organ class, high-level term (HLT), and preferred term (PT) of the version of the Medical Dictionary for Regulatory Activities (MedDRA) used in the respective study.

\subsection{Assessments and Statistical Analyses}

Events per 100 patient-years (PY) and patients with at least one event per $100 \mathrm{PY}$ were assessed during the study treatment period.

Exposure-adjusted rates were used to compare dupilumab treatment $(300 \mathrm{mg} \mathrm{qw}, 300 \mathrm{mg} \mathrm{q} 2 \mathrm{w}$, and combined $\mathrm{qw}+\mathrm{q} 2 \mathrm{w}$ ) with placebo, and $p$ values were obtained from a 
time-to-event exponential regression model with treatment as the only covariate. There was no apparent dose-response relation for infections with the dupilumab qw and $\mathrm{q} 2 \mathrm{w}$ regimens, so statistical comparison of dupilumab versus placebo was carried out using the dupilumab qw and $\mathrm{q} 2 \mathrm{w}$ groups combined.

In addition, for the overall endpoints, the differences between dupilumab and placebo were described separately for the monotherapy studies (R668-AD-1117, EVALUATE, R668-AD-1021, SOLO 1, and SOLO 2) and studies of dupilumab that required concomitant topical corticosteroids (TCS) (CHRONOS and CAFÉ) by using exposure-adjusted rates. Unless otherwise indicated, given the pooling of data from both monotherapy and concomitant therapy studies in the overall analyses, the terms "dupilumab" and "placebo" refer to the study treatments. Finally, numbers (percentage) of patients with $0,1,2,3,4$, and $>4$ events of infections overall, serious or severe infections, non-herpetic skin infections, and herpesviral infections are provided using descriptive statistics.

\section{Results}

\subsection{Patients}

Data from 2932 patients were included in this analysis, of whom 1091 received placebo, 1095 dupilumab $300 \mathrm{mg} \mathrm{qw}$, and 746 dupilumab $300 \mathrm{mg} \mathrm{q} 2 \mathrm{w}$.

\subsection{Exposure-Adjusted Infection Rates}

There were no significant differences between treatment groups in overall infection rates calculated either as the number of patients with at least one infection per $100 \mathrm{PY}$ (Table 1) or in the number of events per 100 PY (Table E3 in the ESM). Rates of events per $100 \mathrm{PY}$ followed a trend similar to those seen for patients with at least one event per $100 \mathrm{PY}$. Approximately 129 patients per $100 \mathrm{PY}$ in the placebo group had at least one infection, compared with approximately 126,134 , and 129 patients per $100 \mathrm{PY}$ in the dupilumab $300 \mathrm{mg} \mathrm{qw}, 300 \mathrm{mg} \mathrm{q} 2 \mathrm{w}$, and combined groups, respectively. Similarly, there were approximately 155 infections per $100 \mathrm{PY}$ in the placebo group and 150, 156, and 152 infections per $100 \mathrm{PY}$ in the dupilumab $300 \mathrm{mg}$ qw, $300 \mathrm{mg} \mathrm{q} 2 \mathrm{w}$, and combined groups, respectively. There were no apparent differences in infection rates between the dupilumab regimens.

Overall, a higher proportion of patients in the placebo group than in the dupilumab group discontinued for any reason $(18.3 \%$ vs. $8.0 \%$, placebo vs. dupilumab combined; 42.59 vs. 18.48 patients per $100 \mathrm{PY}$, respectively; $p<0.0001)$. Very few patients permanently discontinued study treatment because of infections (five patients in the placebo group and three in the dupilumab groups combined), and there were no significant differences in discontinuation rates between treatment groups (Table 1 and Fig. 1a; and Table E3 in the ESM). Infections that led to treatment discontinuation in the placebo group were, by MedDRA PT, cytomegalovirus infection, infected dermatitis, eczema herpeticum, bacterial endocarditis, molluscum contagiosum, sepsis, and septic embolus (one case each; one patient who discontinued had three infectious TEAEs [bacterial endocarditis, sepsis, and septic embolus]). Infections that led to treatment discontinuation in the dupilumab groups were conjunctivitis, eczema impetiginous, and folliculitis (one case each).

Serious or severe infections were uncommon, but significantly less common in the dupilumab groups than in placebo, when assessed either as the number of patients per $100 \mathrm{PY}$ (risk ratio [RR] 0.43, $p=0.02$, dupilumab combined vs. placebo; Table 1 and Fig. 1b) or as the number of events per 100 PY (RR 0.38, $p=0.004$, dupilumab combined vs. placebo; Table E3 in the ESM).

Skin infections (non-herpetic) were significantly less common in the dupilumab groups than in the placebo group, whether assessed as MedDRA HLT (number of patients per 100 PY: RR 0.44, $p<0.001$, dupilumab combined vs. placebo) or as adjudicated skin infections (number of patients per 100 PY: RR 0.55, $p<0.001$, dupilumab combined vs. placebo; Fig. 2a and Table 1; and Table E3 in the ESM). One patient each in the placebo and dupilumab qw groups had an ectoparasitic infection (acarodermatitis).

Non-skin infections (i.e., excluding infections assessed as skin-structure or soft-tissue infections by MedDRA HLT) occurred at similar exposure-adjusted rates in the placebo and dupilumab groups (Table 1; and Table E3 in the ESM). Common non-skin infections (MedDRA PTs) that were more frequent in the dupilumab groups combined than in the placebo group were nasopharyngitis, upper respiratory tract infection, conjunctivitis, oral herpes, and bacterial conjunctivitis; those that were more frequent in the placebo group than in the dupilumab groups combined included urinary tract infection, influenza, gastroenteritis, viral upper respiratory tract infection, and pharyngitis (Table 2). Event rates (Table E4 in the ESM) were broadly similar to patient incidence rates (Table 2).

Systemic or invasive infections were uncommon; of note, one patient in the dupilumab $\mathrm{q} 2 \mathrm{w}$ group had, by MedDRA PT, bacterial sepsis, two patients in the placebo group had sepsis (including one who also had bacterial endocarditis and septic embolus, which led to treatment discontinuation, as noted above), and one patient in the placebo group had a moderate cytomegalovirus infection that led to treatment discontinuation, as noted above. There were no cases of endoparasitic (e.g., helminthic) infections. 
Table 1 Exposure-adjusted numbers of patients with treatment-emergent infections during the study treatment period

\begin{tabular}{|c|c|c|c|c|c|c|c|}
\hline & \multicolumn{4}{|c|}{ Patients with $\geq 1$ event, $\mathrm{nP}(\mathrm{nP} / 100 \mathrm{PY})$} & \multicolumn{3}{|c|}{$\begin{array}{l}\text { Comparison with placebo, risk ratio }(95 \% \text { CI }) \\
p \text { value }^{\mathrm{a}}\end{array}$} \\
\hline & $\begin{array}{l}\text { Placebo } \\
(n=1091)\end{array}$ & $\begin{array}{l}\text { Dupilumab } \\
300 \mathrm{mg} \mathrm{qw} \\
(n=1095)\end{array}$ & $\begin{array}{l}\text { Dupilumab } \\
300 \mathrm{mg} \mathrm{q} 2 \mathrm{w} \\
(n=746)\end{array}$ & $\begin{array}{l}\text { Dupilumab } \\
\text { combined } \\
(n=1841)\end{array}$ & $\begin{array}{l}\text { Dupilumab } \\
300 \mathrm{mg} \mathrm{qw}\end{array}$ & $\begin{array}{l}\text { Dupilumab } \\
300 \mathrm{mg} \mathrm{q} 2 \mathrm{w}\end{array}$ & $\begin{array}{l}\text { Dupilumab } \\
\text { combined }\end{array}$ \\
\hline Overall & $453(129.317)$ & $452(126.486)$ & $287(133.580)$ & 739 (129.149) & $\begin{array}{l}0.98(0.86, \\
1.11) \\
0.74\end{array}$ & $\begin{array}{l}1.03(0.89, \\
1.20) \\
0.67\end{array}$ & $\begin{array}{l}1.00(0.89,1.12) \\
0.98\end{array}$ \\
\hline $\begin{array}{l}\text { Infections leading } \\
\text { to treatment } \\
\text { discontinuation }^{\mathrm{b}}\end{array}$ & $5(0.986)$ & $2(0.382)$ & $1(0.340)$ & $3(0.367)$ & $\begin{array}{l}0.39(0.08, \\
2.00) \\
0.26\end{array}$ & $\begin{array}{l}0.35(0.04 \\
2.95) \\
0.33\end{array}$ & $\begin{array}{l}0.37(0.09,1.56) \\
0.18\end{array}$ \\
\hline $\begin{array}{l}\text { Serious or severe } \\
\text { infections }\end{array}$ & $20(3.978)$ & $7(1.340)$ & $7(2.393)$ & $14(1.718)$ & $\begin{array}{l}0.34(0.14 \\
0.80) \\
0.01\end{array}$ & $\begin{array}{l}0.60(0.25, \\
1.42) \\
0.25\end{array}$ & $\begin{array}{l}0.43(0.22,0.85) \\
0.02\end{array}$ \\
\hline \multicolumn{8}{|c|}{ Non-herpetic skin infections } \\
\hline $\begin{array}{l}\text { Skin structures } \\
\text { and soft tissue } \\
\text { infections }{ }^{c}\end{array}$ & $55(11.255)$ & $23(4.455)$ & $17(5.867)$ & $40(4.963)$ & $\begin{array}{l}0.40(0.24 \\
0.64) \\
<0.001\end{array}$ & $\begin{array}{l}0.52(0.30 \\
0.90) \\
0.02\end{array}$ & $\begin{array}{l}0.44(0.29,0.66) \\
<0.001\end{array}$ \\
\hline $\begin{array}{l}\text { Adjudicated skin } \\
\text { infections }^{\mathrm{d}}\end{array}$ & $122(26.563)$ & $69(13.881)$ & $44(15.672)$ & $113(14.527)$ & $\begin{array}{l}0.52(0.39 \\
0.70) \\
<0.001\end{array}$ & $\begin{array}{l}0.59(0.42 \\
0.83) \\
0.003\end{array}$ & $\begin{array}{l}0.55(0.42,0.71) \\
<0.001\end{array}$ \\
\hline $\begin{array}{l}\text { Non-skin } \\
\text { infections }^{\mathrm{e}}\end{array}$ & $424(117.862)$ & $443(122.416)$ & $281(129.691)$ & $724(125.141)$ & $\begin{array}{l}1.04(0.91 \\
1.19) \\
0.58\end{array}$ & $\begin{array}{l}1.10(0.95 \\
1.28) \\
0.21\end{array}$ & $\begin{array}{l}1.06(0.94,1.20) \\
0.33\end{array}$ \\
\hline \multicolumn{8}{|c|}{ Herpesviral infections } \\
\hline Total & $51(10.379)$ & $57(11.262)$ & $43(15.243)$ & $100(12.687)$ & $\begin{array}{l}1.09(0.74 \\
1.58) \\
0.67\end{array}$ & $\begin{array}{l}1.47(0.98, \\
2.20) \\
0.06\end{array}$ & $\begin{array}{l}1.22(0.87,1.71) \\
0.24\end{array}$ \\
\hline $\begin{array}{l}\text { Clinically impor- } \\
\text { tant (eczema } \\
\text { herpeticum, } \\
\text { herpes zoster) }\end{array}$ & $18(3.590)$ & $3(0.573)$ & $6(2.054)$ & $9(1.104)$ & $\begin{array}{l}0.16(0.05 \\
0.54) \\
0.003\end{array}$ & $\begin{array}{l}0.57(0.23 \\
1.44) \\
0.24\end{array}$ & $\begin{array}{l}0.31(0.14,0.68) \\
0.004\end{array}$ \\
\hline $\begin{array}{l}\text { Eczema herpe- } \\
\text { ticum }\end{array}$ & $12(2.380)$ & $2(0.382)$ & $4(1.368)$ & $6(0.735)$ & $\begin{array}{l}0.16(0.04, \\
0.72) \\
0.02\end{array}$ & $\begin{array}{l}0.57(0.19, \\
1.78) \\
0.34\end{array}$ & $\begin{array}{l}0.31(0.12,0.82) \\
0.02\end{array}$ \\
\hline Herpes zoster & $7(1.384)$ & $1(0.191)$ & $2(0.681)$ & $3(0.367)$ & $\begin{array}{l}0.14(0.02, \\
1.12) \\
0.06\end{array}$ & $\begin{array}{l}0.49(0.10, \\
2.37) \\
0.38\end{array}$ & $\begin{array}{l}0.27(0.07,1.03) \\
0.055\end{array}$ \\
\hline
\end{tabular}

At each level of patient summarization, a patient is counted once if the patient reported $\geq 1$ event. TEAEs included in the analysis were those that occurred during the study treatment period

$C I$ confidence interval, $H L T$ MedDRA high-level term, MedDRA Medical Dictionary for Regulatory Activities, $n P$ number of patients with $\geq 1$ event, $n P / 100 P Y$ number of patients with $\geq 1$ event per $100 \mathrm{PY}, P Y$ patient-years, $q 2 w$ every 2 weeks, $q w$ weekly, $T E A E$ treatment-emergent adverse event

${ }^{\mathrm{a}} p$ values are from a time-to-event exponential regression model with treatment as the only covariate

${ }^{\mathrm{b}}$ Infections that led to treatment discontinuation in the placebo group were cytomegalovirus infection, infected dermatitis, eczema herpeticum, bacterial endocarditis, molluscum contagiosum, sepsis, and septic embolus ( 1 case each; 1 patient who discontinued had 3 infectious TEAEs [bacterial endocarditis, sepsis, and septic embolus]). Infections that led to treatment discontinuation in the dupilumab group were conjunctivitis, eczema impetiginous, and folliculitis (1 case each)

${ }^{\mathrm{c}}$ MedDRA HLT

${ }^{\mathrm{d}}$ Excluding herpesviral infections; data not available for R668-AD-1117

${ }^{\mathrm{e}}$ Includes all infections other than those listed in the MedDRA HLT skin structures and soft tissue infections

Overall rates of herpesviral infections did not differ significantly between placebo and dupilumab groups when assessed as the number of patients with at least one event per $100 \mathrm{PY}$, but when assessed as the number of events per
$100 \mathrm{PY}$, they were slightly more common in the dupilumab $\mathrm{q} 2 \mathrm{w}$ group and the dupilumab groups combined than in the placebo group (Table 1; and Table E3 in the ESM). The clinically important herpesviral infections eczema herpeticum 
Fig. 1 Exposure-adjusted numbers of patients with treatment-emergent infections during the study treatment period. a Infections leading to treatment discontinuation. b Serious or severe infections. At each level of patient summarization, a patient is counted once if the patient reported $\geq 1$ event. Treatment-emergent adverse events included in the analysis were those that occurred during the study treatment period. $p$ values are from a time-to-event exponential regression model with treatment as the only covariate. RRs for significant $p$ values are shown in bold. $C I$ confidence interval, $n P$ number of patients with $\geq 1$ event, $P Y$ patient-years, $q 2 w$ every 2 weeks, $q w$ weekly, $R R$ risk ratio
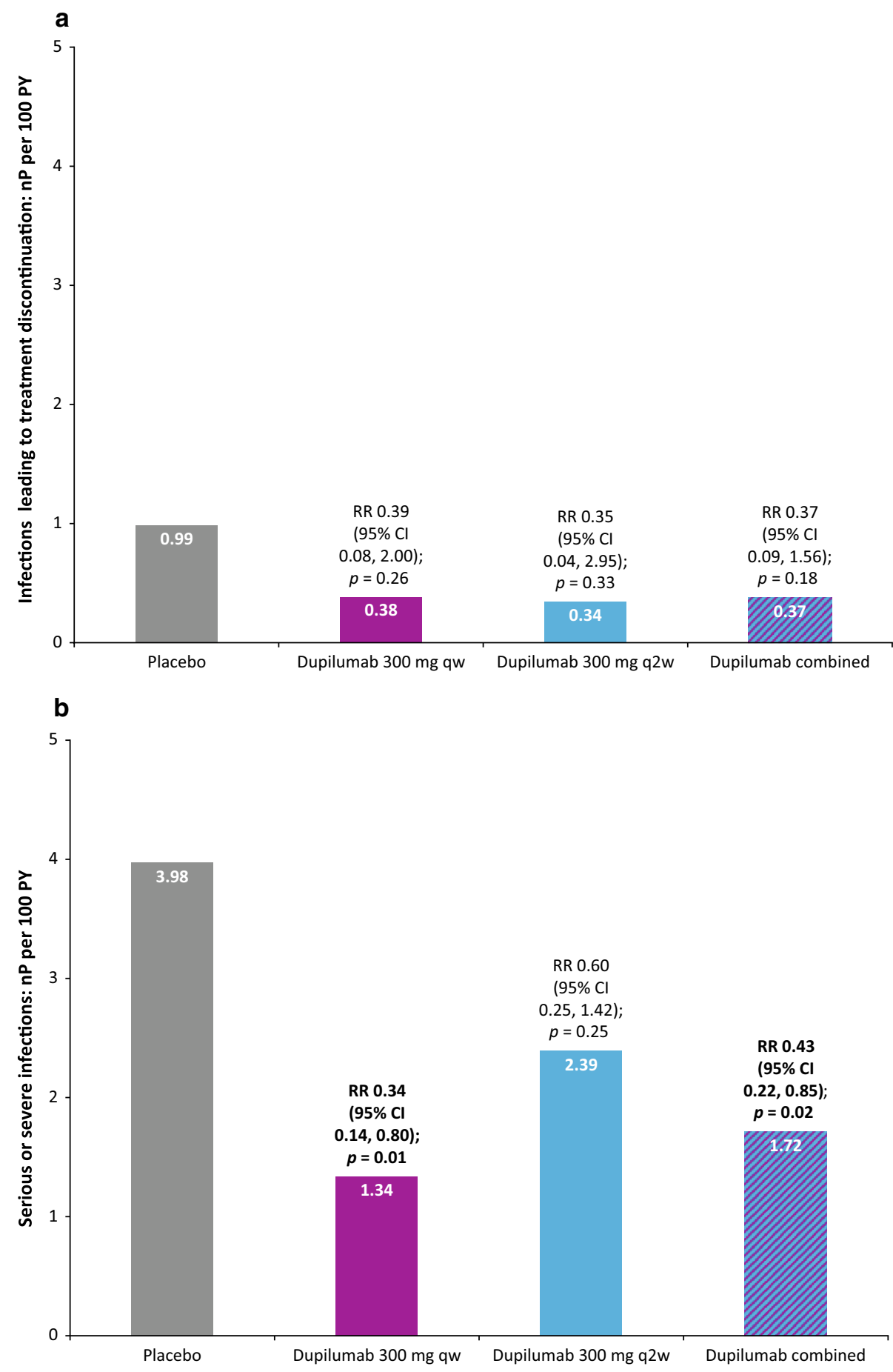

and herpes zoster were both uncommon; eczema herpeticum was significantly more common in the placebo group than in the dupilumab qw or dupilumab combined groups, whether assessed as patients per $100 \mathrm{PY}$ or events per $100 \mathrm{PY}$ (Table 1; and Table E3 in the ESM). The incidence of herpes zoster infection was numerically higher in the placebo group compared with the dupilumab groups (Table 1; and Table E3 in the ESM). However, the combined rate of the clinically important herpesviral infections eczema herpeticum and herpes zoster was significantly higher in the placebo group than in the dupilumab qw group (RR $0.16, p=0.003$ ) or the dupilumab groups combined (RR 0.31, $p=0.004$; Table 1; and Table E3 in the ESM).

The overall patterns of infection in studies in which dupilumab was administered as monotherapy (R668-AD-1117, EVALUATE, R668-AD-1021, SOLO 1, and SOLO 2) or with concomitant TCS (CHRONOS and CAFÉ) were similar to those seen in the full analysis of 
Fig. 2 Exposure-adjusted numbers of patients with treatment-emergent skin infections (non-herpetic) during the study treatment period. a Skin infections by HLT and adjudicated skin infections. b Adjudicated skin infections in monotherapy studies and studies with concomitant TCS. At each level of patient summarization, a patient is counted once if the patient reported $\geq 1$ event. Treatment-emergent adverse events included in the analysis were those that occurred during the study treatment period. $p$ values are from a time-toevent exponential regression model with treatment as the only covariate. RRs for significant $p$ values are shown in bold. $C I$ confidence interval, HLT MedDRA high-level term, MedDRA Medical Dictionary for Regulatory Activities, $n P$ number of patients with $\geq 1$ event, $P Y$ patient-years, $q 2 w$ every 2 weeks, $q w$ weekly, $R R$ risk ratio, TCS topical corticosteroids. ${ }^{\mathrm{a}}$ MedDRA HLT
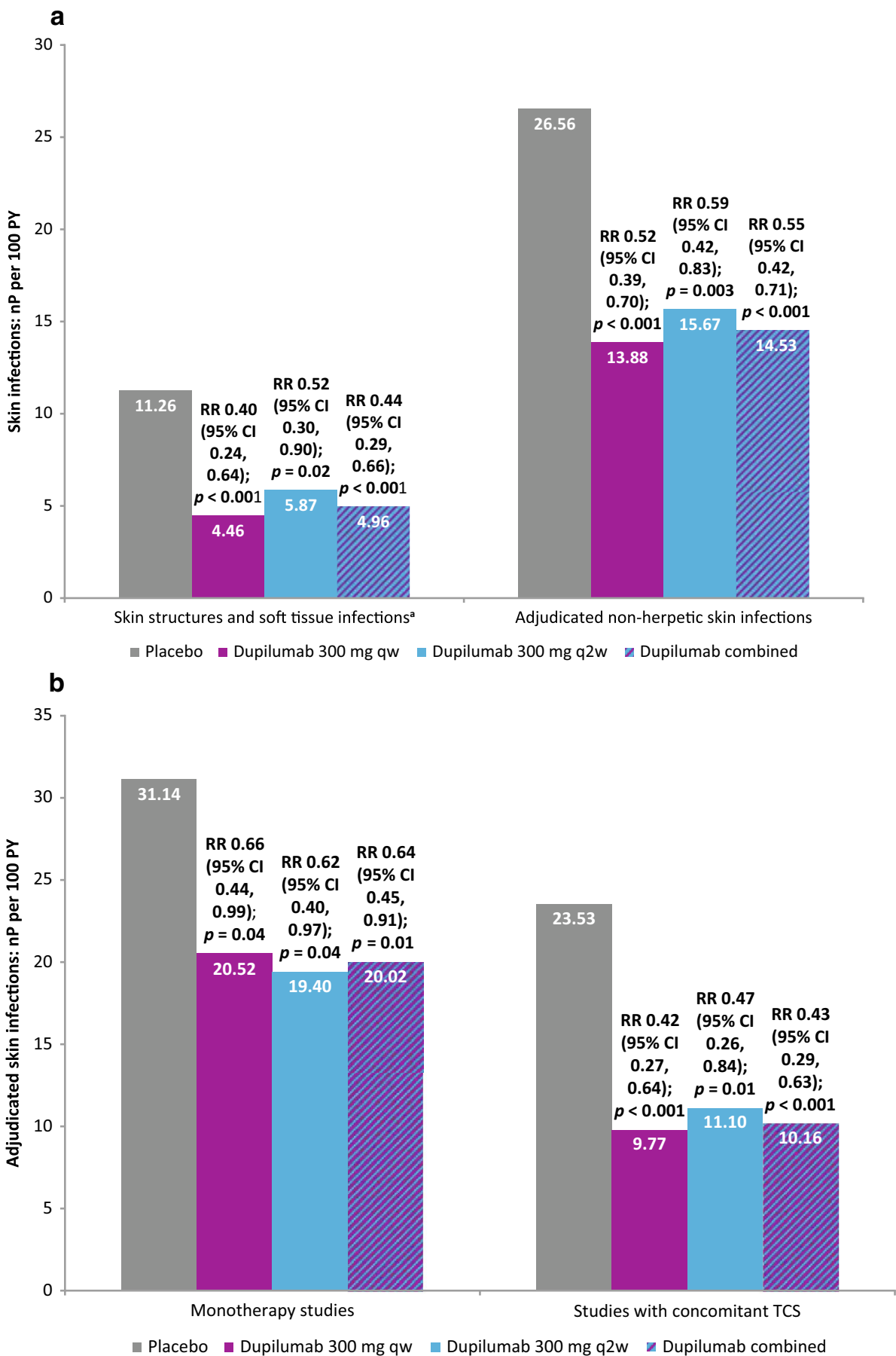

pooled data: in both of these groups of studies there were similar rates of infections overall in the placebo and dupilumab groups, and higher rates of serious or severe infections, non-herpetic skin infections, and clinically important herpesviral infections (eczema herpeticum or herpes zoster) in the placebo groups than in the dupilumab groups (Tables E5 and E6 in the ESM). Skin infections were reported at higher rates in all treatment groups in the monotherapy studies than in the concomitant TCS studies (Fig. 2b).

\subsection{Patients with Multiple Infections}

There were no apparent differences between treatment groups in the percentages of patients with multiple $(\geq 2$ vs. 0 or 1) infections overall, skin infections, or herpesviral infections (Table E7 in the ESM). Multiple total infections were reported in similarly small proportions of patients in the placebo and dupilumab groups. One patient had two serious or severe infections and another had three such events; both patients were in the placebo group. More patients in 
Table 2 Treatment-emergent infections (by MedDRA PT) by incidence rate: number of patients per 100 PY (includes any PT reported in $>5$ patients in the placebo group, dupilumab $300 \mathrm{mg}$ qw group, or dupilumab $300 \mathrm{mg} \mathrm{q} 2 \mathrm{w}$ group)

\begin{tabular}{|c|c|c|c|c|}
\hline \multirow[t]{2}{*}{ Infection (PT) } & \multicolumn{4}{|c|}{ Patients with infection, $\mathrm{nP}(\mathrm{nP} / 100 \mathrm{PY})$} \\
\hline & Placebo $(n=1091)$ & $\begin{array}{l}\text { Dupilumab } 300 \mathrm{mg} \text { qw } \\
(n=1095)\end{array}$ & $\begin{array}{l}\text { Dupilumab } 300 \mathrm{mg} \mathrm{q} 2 \mathrm{w} \\
(n=746)\end{array}$ & $\begin{array}{l}\text { Dupilumab com- } \\
\text { bined }(n=1841)\end{array}$ \\
\hline Nasopharyngitis & $145(31.378)$ & $155(32.835)$ & $102(38.178)$ & $257(34.766)$ \\
\hline Upper respiratory tract infection & $62(12.834)$ & $80(16.254)$ & $30(10.616)$ & $110(14.198)$ \\
\hline Conjunctivitis & $10(1.975)$ & $45(8.732)$ & $33(11.445)$ & $78(9.705)$ \\
\hline Oral herpes & $17(3.376)$ & $36(7.033)$ & $27(9.407)$ & $63(7.886)$ \\
\hline Bacterial conjunctivitis & $9(1.780)$ & $17(3.289)$ & $10(3.429)$ & $27(3.339)$ \\
\hline Sinusitis & $16(3.174)$ & $23(4.493)$ & $4(1.364)$ & $27(3.354)$ \\
\hline Urinary tract infection & $24(4.783)$ & $17(3.283)$ & $10(3.433)$ & $27(3.337)$ \\
\hline Herpes simplex & $10(1.975)$ & $11(2.114)$ & $13(4.475)$ & $24(2.960)$ \\
\hline Influenza & $23(4.600)$ & $15(2.887)$ & $8(2.748)$ & $23(2.837)$ \\
\hline Gastroenteritis & $14(2.788)$ & $13(2.499)$ & $9(3.085)$ & $22(2.709)$ \\
\hline Viral upper respiratory tract infection & $16(3.186)$ & $13(2.516)$ & $6(2.061)$ & $19(2.352)$ \\
\hline Pharyngitis & $18(3.565)$ & $12(2.307)$ & $6(2.047)$ & $18(2.213)$ \\
\hline Rhinitis & $8(1.579)$ & $13(2.506)$ & $5(1.712)$ & $18(2.220)$ \\
\hline Bronchitis & $12(2.373)$ & $9(1.725)$ & $7(2.394)$ & $16(1.965)$ \\
\hline Cystitis & $5(0.986)$ & $8(1.535)$ & $4(1.366)$ & $12(1.474)$ \\
\hline Molluscum contagiosum & $3(0.591)$ & $9(1.734)$ & $2(0.681)$ & $11(1.353)$ \\
\hline Cellulitis & $13(2.578)$ & $8(1.537)$ & $2(0.683)$ & $10(1.230)$ \\
\hline Respiratory tract infection & $5(0.985)$ & $7(1.342)$ & $1(0.340)$ & $8(0.981)$ \\
\hline Tonsillitis & $3(0.591)$ & $6(1.149)$ & $2(0.681)$ & $8(0.981)$ \\
\hline Gastroenteritis viral & $8(1.577)$ & $3(0.574)$ & $4(1.365)$ & $7(0.858)$ \\
\hline Conjunctivitis viral & $2(0.393)$ & $1(0.191)$ & $5(1.708)$ & $6(0.735)$ \\
\hline Eczema herpeticum & $12(2.380)$ & $2(0.382)$ & $4(1.368)$ & $6(0.735)$ \\
\hline Furuncle & $8(1.582)$ & $1(0.191)$ & $5(1.715)$ & $6(0.736)$ \\
\hline Staphylococcal skin infection & $7(1.382)$ & $3(0.574)$ & $3(1.025)$ & $6(0.736)$ \\
\hline Otitis externa & $10(1.980)$ & $3(0.574)$ & $2(0.681)$ & $5(0.613)$ \\
\hline Herpes zoster & $7(1.384)$ & $1(0.191)$ & $2(0.681)$ & $3(0.367)$ \\
\hline Bacterial skin infection & $12(2.374)$ & $2(0.383)$ & 0 & $2(0.245)$ \\
\hline
\end{tabular}

At each level of patient summarization, a patient is counted once if the patient reported $\geq 1$ event. TEAEs included in the analysis were those that occurred during the study treatment period

MedDRA Medical Dictionary for Regulatory Activities, $n P$ number of patients with $\geq 1$ event, $n P / 100 P Y$ number of patients with $\geq 1$ event per 100 PY, $P T$ MedDRA preferred term, $P Y$ patient-years, $q 2 w$ every 2 weeks, $q w$ weekly, $T E A E$ treatment-emergent adverse event

the placebo group than in the dupilumab groups had two or more skin infections (whether assessed as the HLT skin structures and soft tissue infections or as adjudicated skin infections). Multiple herpesviral infections were reported in very small proportions of patients in the placebo group and in the dupilumab groups combined.

\subsection{Anti-Infective Medications}

Concomitant systemic anti-infective medications were used significantly less by patients in the dupilumab groups than in the placebo group (RR $0.78, p=0.002$, dupilumab combined vs. placebo; Fig. 3).

\section{Discussion}

In this pooled analysis, dupilumab- and placebo-treated patients did not significantly differ in their rates of overall infections or discontinuation due to infections, whereas serious or severe infections, skin infections, and clinically important herpesviral infections (eczema herpeticum or herpes zoster) occurred at lower rates in the dupilumab groups than in the placebo group. Fewer systemic anti-infectives were used in the dupilumab groups than in the placebo group. There were no differences in infection rates overall between dupilumab regimens. Pooling data from multiple studies increased the sample size and thereby increased the 
precision of the analysis, thus providing the opportunity to confirm or refute trends noted in individual studies and enhancing the ability to detect rare events. Outcomes of this pooled data analysis are consistent with those of the individual studies, and no new safety signals were detected [47-52].

In this pooled data analysis, dupilumab, compared with placebo, reduces rates of skin infections, consistent with the individual studies [47-52]; differences between the pooled groups were nominally statistically significant. The aggregate rate of skin infections in pooled placebo groups in this analysis are consistent with placebo-group rates in clinical trials of other therapies in similar populations [54], reflecting the considerable burden of skin infections in moderate-to-severe AD. Skin infections are common in patients with $\mathrm{AD}$ and more so in patients with severe disease [4, 5, 11-13, 54-56]. Several aspects of the pathobiology of AD may increase patients' susceptibility to skin infections, including skin barrier dysfunction, skin damage associated
Fig. 3 Systemic anti-infective medication use. a Number of patients with $\geq 1$ use of systemic anti-infective medication per 100 PY. b Systemic antiinfective medication use by number of events per $100 \mathrm{PY}$. RRs for significant $p$ values are shown in bold. $C I$ confidence interval, $n E$ number of events, $n P$ number of patients with $\geq 1$ event, $P Y$ patient-years, $q 2 w$ every 2 weeks, $q w$ weekly, $R R$ risk ratio
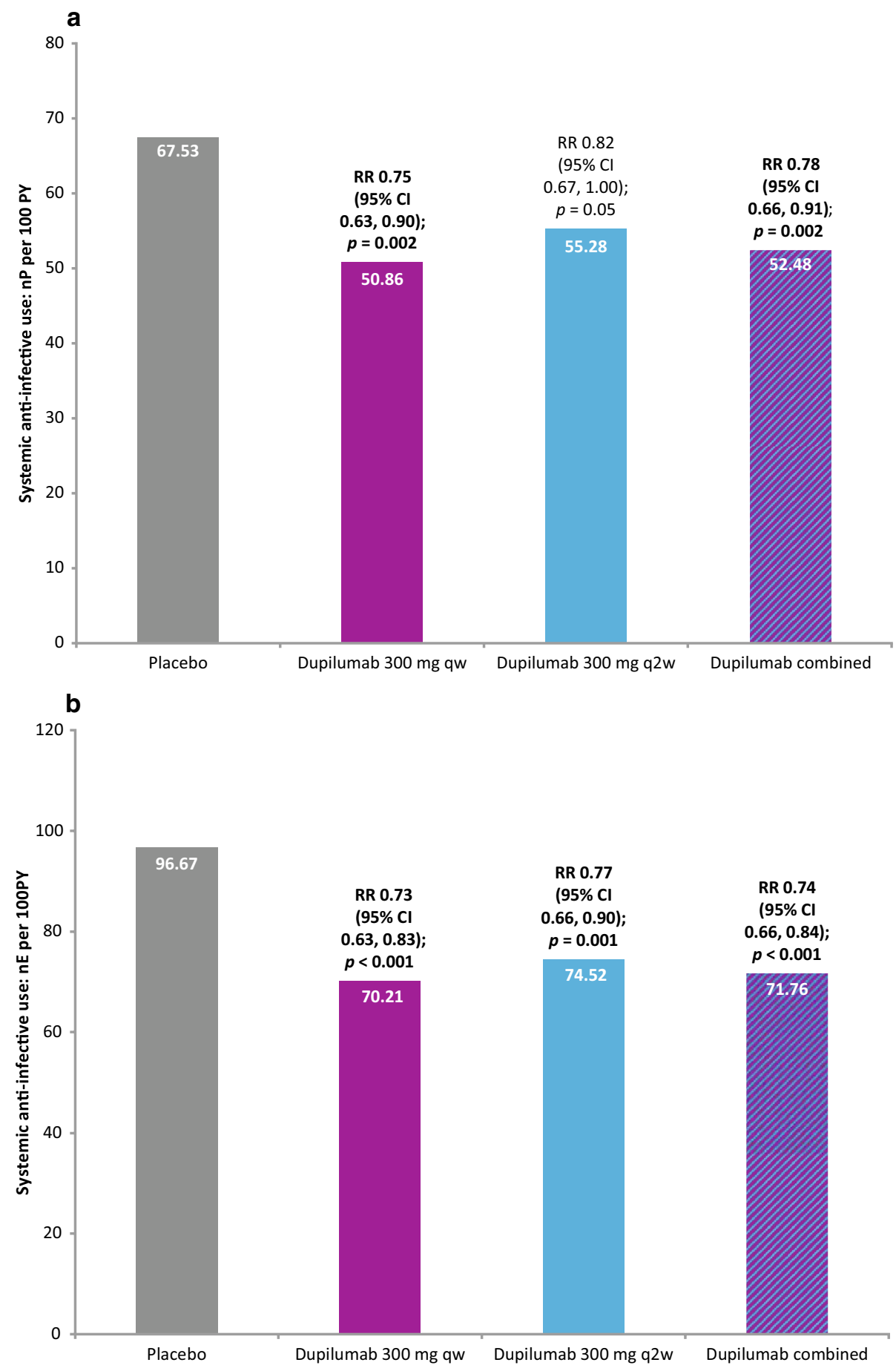
with scratching, alterations in the skin microbiome, and a reduced expression of antimicrobial peptides $[4,11,55,56]$. Impairment of the epidermal barrier function results in part from the overexpression of type 2 cytokines and imbalance of the skin microbiome [56]. Therefore, the lower incidence of skin infections in dupilumab-treated patients compared with placebo-treated patients may be a result of several mechanisms, including dupilumab-mediated improvement of skin barrier function (either indirectly through inhibition of type 2 cytokines or directly through a reduction in mechanical damage to the skin caused by scratching) and favorable changes to the microbiome. Indeed, dupilumab reduces the abundance of $S$. aureus and increases microbial diversity on lesional and non-lesional skin in patients with $\mathrm{AD}$ [57].

Rates of serious or severe infections were significantly lower in the dupilumab groups combined than in the placebo group, and there was no evidence of an increase in risk of opportunistic infections with dupilumab. Serious and severe infections were grouped on the basis that these categories probably overlap. Overall, rates of serious or severe infection were low in this analysis, especially compared with rates reported with immunosuppressive medications [58-61]. The risks of extracutaneous and invasive infections can be increased by systemic medications with a broad immunosuppressive effect, such as corticosteroids and non-steroidal immunosuppressants (e.g., cyclosporine, methotrexate, azathioprine, mycophenolates, and JAK inhibitors), medications that may be used in patients with moderate-to-severe $\mathrm{AD}$ (or are in development for AD) [11, 30, 58, 60, 62, 63].

Biologic agents that target the immunologic pathways associated with $\mathrm{AD}$ and other atopic diseases provide potentially more specific and effective therapeutic approaches than use of broad systemic immunosuppressants $[64,65]$. However, in clinical experience, type 1 immunity-suppressing biologics in rheumatologic and dermatologic disorders are associated with an increased risk of infection in general, and with increased risks of serious extracutaneous and systemic infections such as tuberculosis, bacterial sepsis, opportunistic infections, and invasive fungal infections (e.g., histoplasmosis) [31-46, 66]. These biologics are mainly TNF- $\alpha$ and IL-17 inhibitors and affect type 1 immune responses important in host immunity [40, 41]. Indeed, some biologics used to treat psoriasis have boxed warnings of the risk of serious infections, and many biologics, including TNF- $\alpha$ inhibitors (e.g., adalimumab, infliximab, etanercept, and certolizumab pegol), IL-17 inhibitors (secukinumab and ixekizumab), and IL-12/IL-23 inhibitors (ustekinumab and guselkumab), carry a requirement for patient testing for tuberculosis before use [31-38].

In contrast to other biologics, dupilumab targets the activity of IL-4 and IL-13, cytokines important in type 2 immune pathways, which are not crucial to host defense mechanisms against most infectious agents, except endoparasites, specifically intestinal helminths [67-70]. This analysis of pooled data from dupilumab studies revealed no parasitic infections other than one case each of ectoparasitic infection (acarodermatitis) in the placebo group and the dupilumab qw group; none of the studies included in this analysis reported tuberculosis infections or reactivations. Of note, dupilumab did not have an impact on T-cell- and B-cell-mediated (or non-Tcell-mediated) antibody response in a clinical trial using two non-live vaccines (tetanus toxoid, reduced diphtheria toxoid, and acellular pertussis vaccine; and quadrivalent meningococcal polysaccharide vaccine) [50]. Direct evidence supporting the safety of administering live vaccines in patients treated with dupilumab is not yet available.

The overall incidence of total herpesviral infections was low in all groups. Herpesviral infection incidence rates overall were slightly higher in the dupilumab groups than in the placebo group, but the difference was small $(<1 \%)$. Oral herpes (herpes labialis) accounted for most of the herpesviral infections. The molecular basis of herpes simplex viral reactivation is poorly understood, but the external triggers are fairly well characterized (e.g., sun exposure, stress) [71-73]. Notably, the incidences of eczema herpeticum and herpes zoster were higher in the placebo group than in the dupilumab groups. The higher rate of eczema herpeticum in the placebo group reflects the increased risk of this clinically important and dangerous herpesviral infection in patients with $\mathrm{AD}$, an infection reported to occur in approximately $3 \%$ of patients with $\mathrm{AD}$ [14]. Patients affected by eczema herpeticum tend to have type 2-dominant disease [6], and the smaller number of events of this infection in the dupilumab groups is consistent with the mechanism of action of dupilumab, which inhibits signaling of IL-4 and IL-13, key drivers of type 2 immune diseases.

There were few differences between the dupilumab and placebo groups in the incidences of specific types of infectious disease as described by PTs. One exception was conjunctivitis, which was more common in dupilumabtreated patients than placebo-treated patients. However, the MedDRA PT "conjunctivitis" represents conjunctivitis of unspecified or undetermined etiology and defaults to the "Infections and Infestations" system organ class in MedDRA. Based on feedback from investigators through the data query process in these clinical trials, most of the adverse events coded as the PT "conjunctivitis" appeared to be non-infectious, but otherwise of unclear etiology. Indeed, there were no statistically significant differences between the dupilumab and placebo groups in the incidences of PTdefined conjunctivitis with specified bacterial or viral etiology. Current data indicate that dupilumab is associated with an increased incidence of conjunctivitis (all etiologies and clinical phenotypes combined) in patients with moderate-tosevere AD [48-52]; notably, no such increase was observed with dupilumab in studies of asthma [25-27] or CRSwNP [28], suggesting that this phenomenon is specific to the AD setting. As a result, adverse events of conjunctivitis of 
undetermined etiology (PT "conjunctivitis") that were classified as infections by the default MedDRA coding pathway may have slightly inflated the rate of overall infections in this pooled analysis, mostly for dupilumab-treated patients. A detailed report of conjunctivitis adverse events in dupilumab clinical trials provides an in-depth analysis of these events [74].

Dupilumab monotherapy studies and studies that required use of concomitant TCS had similar patterns of infection rates overall. In contrast, rates of skin infections were higher in all treatment groups in the monotherapy studies than in the studies that required concomitant TCS use, an observation suggesting that concomitant TCS provides a benefit additional to that of dupilumab in preventing skin infections, perhaps through incremental additional improvement in overall skin condition [48-52].

Multiple infections were uncommon. The placebo and dupilumab groups contained similar proportions of patients with multiple infections overall. In contrast, the placebo groups had higher proportions of patients with multiple skin infections, a finding consistent with higher overall rates of skin infections in the placebo group than in the dupilumab groups.

Meta-analyses of infections in dupilumab clinical trials have reported similar outcomes [75, 76]. However, compared with those meta-analyses, the present pooled analysis was more thorough, with full access to the clinical database and raw data, and thus was more robust, with more complete information than the previously published meta-analyses [3, 4], which were based only on published data.

Our analysis has some limitations. Although this pooled analysis provides data on a large number of patients, including a robust control group, there are also some limitations in this analysis, including those related to MedDRA terminology. A higher dropout rate in the placebo group may have resulted in an underestimation of infection rates, because it limited the opportunity to observe randomly occurring adverse events, including infections. Exposure-adjusted analyses mitigate, but do not completely remove, this bias in favor of placebo, particularly in the analysis of recurring events. This analysis was limited to randomized, placebocontrolled clinical trials, which enabled comparison of placebo- and dupilumab-treated patients, but the numbers of patients may still be too small to identify risks associated with rare events. As the population of patients treated with dupilumab increases over time, further data will become available on these risks. There were no endoparasitic infections (e.g., helminthic infections) reported in this analysis; however, the studies were conducted mostly in North America and Europe and did not include known endemic regions for parasites. Type 2 immunity is a key component of anti-helminthic host defense [77, 78], so further data are needed in patients from regions endemic for these types of parasitic infections. The results of our infection analyses used pooled data from the safety analysis sets and did not account for the effects of rescue medication, which was used by considerably more patients in the placebo group than in the dupilumab groups. In most cases, the rescue medication was TCS, which could potentially reduce the incidence of skin infections by reducing inflammation or altering the microbiome [79]. On the other hand, TCS could exacerbate infections by inhibiting healing [80]. This situation reflects real-world treatment paradigms, in which patients may receive additional medications to their baseline treatment in case of $\mathrm{AD}$ exacerbation. Because few patients received immunosuppressants as rescue medication, we did not perform subgroup analyses by immunosuppressant use; such subgroup analyses would have had a very small sample and therefore could not provide much insight into any additional impact of rescue immunosuppressant use on infection risk.

\section{Conclusions}

Rates of serious or severe infections and bacterial nonherpetic skin infections were significantly lower in the dupilumab groups compared with the placebo group, in this pooled analysis of data from phase II and phase III clinical trials of dupilumab. There was no significant difference between dupilumab and placebo groups in overall infection rates, and overall, there were no differences in infection rates between the dupilumab regimens. The dupilumab groups had lower use of systemic anti-infective medications than the placebo group. Overall, herpesviral infections were more common in the dupilumab $300 \mathrm{mg} \mathrm{q} 2 \mathrm{w}$ and dupilumab groups combined, versus the placebo group, but the clinically more concerning eczema herpeticum and herpes zoster infections were less common with dupilumab than with placebo. The results of this analysis support the safety of dupilumab for the treatment of moderate-to-severe $\mathrm{AD}$ in adults, and the larger sample provided by pooling data showed no new safety signals.

Acknowledgements The authors thank the patients and their families for their participation in these studies; their colleagues for their support; and Linda Williams (Regeneron Pharmaceuticals, Inc.) and ElBdaoui Haddad (Sanofi Genzyme) for their contributions.

Data Availability Qualified researchers may request access to study documents (including the clinical study report, study protocol with any amendments, blank case report form, and statistical analysis plan) that support the methods and findings reported in this manuscript. Individual anonymized participant data will be considered for sharing once the indication has been approved by a regulatory body, if there is legal authority to share the data and there is not a reasonable likelihood of participant re-identification. Submit requests to https://errs.regeneron. com/external. 


\section{Compliance with Ethical Standards}

Ethics All studies were conducted in accordance with the ethical principles that have their origin in the Declaration of Helsinki and that are consistent with the International Council for Harmonisation guidelines for Good Clinical Practice and applicable regulatory requirements [4752]. All patients provided written informed consent before participating in the studies. The studies' ClinicalTrials.gov identifiers are as follows: NCT01548404, NCT02210780, NCT01859988, NCT02277743, NCT02277769, NCT02260986, and NCT02755649.

Funding This research was sponsored by Sanofi and Regeneron Pharmaceuticals, Inc. The study sponsors participated in the study design collection, analysis, and interpretation of data; writing of the report; and the decision to submit the article for publication. Medical writing/ editorial assistance was provided by Vicki Schwartz, $\mathrm{PhD}$, and Manuela Pigors, PhD, of Excerpta Medica, funded by Sanofi Genzyme and Regeneron Pharmaceuticals, Inc.

Conflict of interest L. F. Eichenfield has received honoraria for consulting services from Almirall, Celgene, Dermira, Dermavant, Eli Lilly and Company, Forté Pharma, Galderma, L'Oréal, Incyte, MatriSys, Menlo Therapeutics, Otsuka, Novan, Novartis, Pfizer, Regeneron Pharmaceuticals, Inc., Sanofi Genzyme, and Valeant/Ortho Dermatologics; and study support (to institution) from Celgene, Dermira, Dermavant, Eli Lilly and Company, Galderma, Incyte, Medimetriks, Pfizer, Regeneron Pharmaceuticals, Inc., Sanofi Genzyme, and Valeant. T. Bieber is a speaker for Almirall, Anacor, Astellas, Celgene, Chugai, Galderma, Janssen-Cilag, L'Oréal, Novartis, Oxagen, Pfizer, Regeneron Pharmaceuticals, Inc., and Sanofi. L. A. Beck has received honoraria as a consultant and research grants as principal investigator for clinical trials from AbbVie, Pfizer, Realm Therapeutics, and Regeneron Pharmaceuticals, Inc.; has received honoraria as a consultant from AbbVie, Astra-Zeneca, Allakos, Boehringer-Ingelheim, Celgene, Eli Lilly and Company, GSK, Leo Pharma, Novan, Novartis, Realm Therapeutics, Regeneron, Sanofi, and UCB; and is a stockholder in Medtronic and Pfizer. E. L. Simpson has received honoraria for consulting services from AbbVie, Anacor, Celgene, Dermira Pharmaceutical Co., Eli Lilly and Company, Galderma, Genentech, Inc., GSK, LEO Pharma, Menlo Therapeutics, Pfizer, Inc., Regeneron Pharmaceuticals, Inc., Sanofi Genzyme, and Valeant Pharmaceutical Co.; and has received study support from Anacor, Eli Lilly and Company, GSK, MedImmune, Novartis, Regeneron Pharmaceuticals, Inc., Roivant Sciences, Tioga Pharmaceuticals, Inc., and Vanda Pharmaceuticals, Inc. D. Thaçi has received research support from AbbVie, Almirall, Amgen, Boehringer-Ingelheim, Celgene, Dignity, Eli Lilly and Company, GSK, Janssen-Cilag, LEO Pharma, MSD, Novartis, Pfizer, Inc., Regeneron Pharmaceuticals, Inc., Sandoz, and Sanofi; received honoraria and is an independent advisor for AbbVie, Celgene, Janssen, La Roche-Posay, LEO Pharma, Medac, Novartis, Pfizer, Inc., Sun Pharma, and UCB; received honoraria and is a consultant for AbbVie, Celgene, Dignity, Galápagos, Novartis, Pfizer, Inc., Regeneron Pharmaceuticals, Inc., Sanofi, and UCB; and received honoraria and is an advisory board member for AbbVie, Amgen, Celgene, Eli Lilly and Company, GSK, Janssen, LEO Pharma, Mundipharma, Novartis, Pfizer, Inc., Regeneron Pharmaceuticals, Inc., Sandoz, Sanofi, and UCB. M. de Bruin-Weller is a principal investigator, advisory board member, and consultant for Regeneron Pharmaceuticals, Inc., and Sanofi Genzyme; and a principal investigator and advisory board member for AbbVie. M. Deleuran has received research support, consulting/advisory board agreements, and/or honoraria for lecturing from AbbVie, Eli Lilly and Company, LEO Pharma, Meda, Pierre Fabre, Regeneron Pharmaceuticals, Inc., and Sanofi. J. I. Silverberg has received honoraria for advisory board participation, as a speaker, and for consultancy from AbbVie, Eli Lilly and Company, Galderma, GSK, Kiniksa, LEO Pharma, Menlo Thera- peutics, Pfizer, Realm Therapeutics, Regeneron Pharmaceuticals, Inc., Roivant, and Sanofi; and research grants from GSK, Regeneron Pharmaceuticals, Inc., and Sanofi. C. Ferrandiz is a principal investigator in clinical trials for AbbVie, Sanofi, LEO Pharma; and an advisory board participant for Sanofi. R. Fölster-Holst is an investigator for studies, speaker, and consultant for Astellas, Almirall Hermal, Beiersdorf, Johnson \& Johnson, La Roche-Posay, LEO Pharma, Neubourg Skin Care GmbH, Novartis, Pierre Fabre, Procter \& Gamble, and Regeneron Pharmaceuticals, Inc. Z. Chen, N.M.H. Graham, B. Akinlade, G.D. Yancopoulos, and M. Ardeleanu are employees of and shareholders in Regeneron Pharmaceuticals, Inc. G. Pirozzi is an employee of and may hold stock and/or stock options in Sanofi.

Open Access This article is distributed under the terms of the Creative Commons Attribution-NonCommercial 4.0 International License (http://creativecommons.org/licenses/by-nc/4.0/), which permits any noncommercial use, distribution, and reproduction in any medium, provided you give appropriate credit to the original author(s) and the source, provide a link to the Creative Commons license, and indicate if changes were made.

\section{References}

1. Gandhi NA, Bennett BL, Graham NM, Pirozzi G, Stahl N, Yancopoulos GD. Targeting key proximal drivers of type 2 inflammation in disease. Nat Rev Drug Discov. 2016;15:35-50.

2. Czarnowicki T, Krueger JG, Guttman-Yassky E. Skin barrier and immune dysregulation in atopic dermatitis: an evolving story with important clinical implications. J Allergy Clin Immunol Pract. 2014;2:371-9.

3. Boguniewicz M, Alexis AF, Beck LA, Block J, Eichenfield LF, Fonacier L, et al. Expert perspectives on management of moderate-to-severe atopic dermatitis: a multidisciplinary consensus addressing current and emerging therapies. J Allergy Clin Immunol Pract. 2017;5:1519-31.

4. Bieber T. Atopic dermatitis. N Engl J Med. 2008;358:1483-94.

5. Totté JE, van der Feltz WT, Hennekam M, van Belkum A, van Zuuren EJ, Pasmans SG. Prevalence and odds of Staphylococcus aureus carriage in atopic dermatitis: a systematic review and meta-analysis. Br J Dermatol. 2016;175:687-95.

6. Beck LA, Boguniewicz M, Hata T, Schneider LC, Hanifin J, Gallo $\mathrm{R}$, et al. Phenotype of atopic dermatitis subjects with a history of eczema herpeticum. J Allergy Clin Immunol. 2009;124:260-9.

7. Leung DY, Gao PS, Grigoryev DN, Rafaels NM, Streib JE, Howell MD, et al. Human atopic dermatitis complicated by eczema herpeticum is associated with abnormalities in IFN- $\gamma$ response. $\mathbf{J}$ Allergy Clin Immunol. 2011;127:965-73.

8. Howell MD, Gao P, Kim BE, Rafaels NM, Streib JE, Howell $\mathrm{MD}$, et al. The signal transducer and activator of transcription 6 gene (STAT6) increases the propensity of patients with atopic dermatitis toward disseminated viral skin infections. J Allergy Clin Immunol. 2011;128:1006-14.

9. Gao L, Bin L, Rafaels NM, Huang L, Potee J, Ruczinski I, et al. Targeted deep sequencing identifies rare loss-of-function variants in IFNGR1 for risk of atopic dermatitis complicated by eczema herpeticum. J Allergy Clin Immunol. 2015;136:1591-600.

10. De Benedetto A, Agnihothri R, McGirt LY, Bankova LG, Beck LA. Atopic dermatitis: a disease caused by innate immune defects? J Investig Dermatol. 2009;129:14-30.

11. Ong PY, Leung DY. Bacterial and viral infections in atopic dermatitis: a comprehensive review. Clin Rev Allergy Immunol. 2016;51:329-37. 
12. Hata TR, Gallo RL. Antimicrobial peptides, skin infections, and atopic dermatitis. Semin Cutan Med Surg. 2008;27:144-50.

13. Salah LA, Faergemann J. A retrospective analysis of skin bacterial colonisation, susceptibility and resistance in atopic dermatitis and impetigo patients. Acta Derm Venereol. 2015;95:532-5.

14. Leung DY. Why is eczema herpeticum unexpectedly rare? Antiviral Res. 2013;98:153-7.

15. Reed JL, Scott DE, Bray M. Eczema vaccinatum. Clin Infect Dis. 2012;54:832-40.

16. Hsu DY, Shinkai K, Silverberg JI. Epidemiology of eczema herpeticum in hospitalized US children: analysis of a nationwide cohort. J Investig Dermatol. 2018;138:265-72.

17. Langan SM, Abuabara K, Henrickson SE, Hoffstad O, Margolis DJ. Increased risk of cutaneous and systemic infections in atopic dermatitis-a cohort study. J Investig Dermatol. 2017;137:1375-7.

18. Narla S, Silverberg JI. Association between atopic dermatitis and serious cutaneous, multiorgan and systemic infections in US adults. Ann Allergy Asthma Immunol. 2018;120:66-72.

19. Serrano L, Patel KR, Silverberg J. Association between atopic dermatitis and extracutaneous bacterial and mycobacterial infections: a systematic review and meta-analysis. J Am Acad Dermatol. 2019;80:904-12.

20. MacDonald LE, Karow M, Stevens S, Auerbach W, Poueymirou WT, Yasenchak J, et al. Precise and in situ genetic humanization of $6 \mathrm{Mb}$ of mouse immunoglobulin genes. Proc Natl Acad Sci USA. 2014;111:5147-52.

21. Murphy AJ, Macdonald LE, Stevens S, Karow M, Dore AT, Pobursky K, et al. Mice with megabase humanization of their immunoglobulin genes generate antibodies as efficiently as normal mice. Proc Natl Acad Sci USA. 2014;111:5153-8.

22. DUPIXENT ${ }^{\circledR}$ (dupilumab) Injection. Package insert. Regeneron Pharmaceuticals, Inc., Tarrytown, NY; Sanofi-Aventis U.S., Bridgewater, NJ; 2019. https://www.regeneron.com/sites/default/ files/Dupixent_FPI.pdf. Accessed 13 Mar 2019.

23. DUPIXENT ${ }^{\circledR}$ (dupilumab) Injection. Package insert. Tarrytown, NY, USA: Regeneron Pharmaceuticals, Inc.; Tokyo, Japan: Sanofi K.K.

24. European Medicines Agency. Annex I. Summary of product characteristics [dupilumab]. http://www.ema.europa.eu/documents/ product-information/dupixent-epar-product-information_en.pdf. Accessed 10 Mar 2019.

25. Wenzel S, Castro M, Corren J, Maspero J, Wang L, Zhang B, et al. Dupilumab efficacy and safety in adults with uncontrolled persistent asthma despite use of medium-to-high-dose inhaled corticosteroids plus a long-acting $\beta 2$ agonist: a randomised double-blind placebo-controlled pivotal phase $2 \mathrm{~b}$ dose-ranging trial. Lancet. 2016;388:31-44

26. Castro M, Corren J, Pavord I, Maspero J, Wenzel S, Rabe K, et al. Dupilumab efficacy and safety in moderate-to-severe uncontrolled asthma. N Engl J Med. 2018;378:2486-96.

27. Rabe K, Nair P, Brusselle G, Maspero J, Castro M, Sher L, et al. Efficacy and safety of dupilumab in glucocorticoid-dependent severe asthma. N Engl J Med. 2018;378:2475-85.

28. Bachert C, Mannent L, Naclerio RM, Mullol J, Ferguson BJ, Gevaert $\mathrm{P}$, et al. Effect of subcutaneous dupilumab on nasal polyp burden in patients with chronic sinusitis and nasal polyposis: a randomized clinical trial. JAMA. 2016;315:469-79.

29. Hirano I, Dellon ES, Hamilton JD, Collins MH, Peterson K, Chehade M, et al. Dupilumab efficacy and safety in adult patients with active eosinophilic esophagitis: a randomized double-blind placebo-controlled phase 2 trial [Late-breaking abstract 20]. In: World Congress of Gastroenterology at ACG 2017, 13-18 Oct, 2017, Orlando, FL.
30. Cinats A, Heck E, Robertson L. Janus kinase inhibitors: a review of their emerging applications in dermatology. Skin Ther Lett. 2018;23:5-9.

31. ENBREL $^{\circledR}$ (etanercept) Injection. Prescribing information. Thousand Oaks, CA: Immunex Corporation/AMGEN; 2016. http:// www.pi.amgen.com/ /media/amgen/repositorysites/pi-amgen -com/enbrel/enbrel_pi.pdf. Accessed 10 Mar 2019.

32. HUMIRA ${ }^{\circledR}$ (adalimumab) Injection. Prescribing information. North Chicago, IL: AbbVie, Inc.; 2017. http://www.rxabbvie. com/pdf/humira.pdf. Accessed 10 Mar 2019.

33. REMICADE ${ }^{\circledR}$ (infliximab) Injection. Package insert. Horsham, PA: Janssen Biotech, Inc.; 2015. http://www.janssenlabels.com/ package-insert/product-monograph/prescribing-information/ REMICADE-pi.pdf. Accessed 10 Mar 2019.

34. STELARA ${ }^{\circledR}$ (ustekinumab) Injection. Prescribing information. Horsham, PA: Janssen Biotech, Inc.; 2017. http://www.janssenlab els.com/package-insert/product-monograph/prescribing-infor mation/STELARA-pi.pdf. Accessed 10 Mar 2019.

35. TREMFYA ${ }^{\circledR}$ (guselkumab) Injection. Prescribing information. Horsham, PA: Janssen Biotech, Inc.; 2019. http://www.janssenlab els.com/package-insert/product-monograph/prescribing-infor mation/TREMFYA-pi.pdf. Accessed 10 Mar 2019.

36. CIMZIA $^{\circledR}$ (certolizumab pegol) Injection. Prescribing Information. Smyrna, GA: ICB, Inc.; 2018. http://www.accessdata.fda. gov/drugsatfda_docs/label/2018/125160s2831bl.pdf\#page $=37$. Accessed 10 Mar 2019.

37. COSENTYX ${ }^{\circledR}$ (secukinumab) Injection. Prescribing information. East Hanover, NJ: Novartis Pharmaceuticals Corporation; 2018. http://www.pharma.us.novartis.com/sites/www.pharma.us.novar tis.com/files/cosentyx.pdf. Accessed 10 Mar 2019.

38. TALTZ ${ }^{\circledR}$ (ixekizumab) Injection. Prescribing information. Indianapolis, IN: Eli Lilly and Company; 2018. http://www.acces sdata.fda.gov/drugsatfda_docs/label/2018/125521s009lbl.pdf. Accessed 10 March 2019.

39. Souto A, Maneiro JR, Salgado E, Carmona L, Gomez-Reino JJ. Risk of tuberculosis in patients with chronic immune-mediated inflammatory diseases treated with biologics and tofacitinib: a systematic review and meta-analysis of randomized controlled trials and long-term extension studies. Rheumatology (Oxford). 2014;53:1872-85

40. Her M, Kavanaugh A. Alterations in immune function with biologic therapies for autoimmune disease. J Allergy Clin Immunol. 2016;137:19-27.

41. Armstrong AW, Bukhalo M, Blauvelt A. A clinician's guide to the diagnosis and treatment of candidiasis in patients with psoriasis. Am J Clin Dermatol. 2016;17:329-36.

42. Dobry AS, Quesenberry CP, Ray GT, Geier JL, Asgari MM. Serious infections among a large cohort of subjects with systemically treated psoriasis. J Am Acad Dermatol. 2017;77:838-44.

43. Garcia-Doval I, Cohen AD, Cazzaniga S, Feldhamer I, Addis A, Carretero G, et al. Risk of serious infections, cutaneous bacterial infections, and granulomatous infections in patients with psoriasis treated with anti-tumor necrosis factor agents versus classic therapies: prospective meta-analysis of Psonet registries. J Am Acad Dermatol. 2017;76:299-308.

44. Saunte DM, Mrowietz U, Puig L, Zachariae C. Candida infections in patients with psoriasis and psoriatic arthritis treated with interleukin-17 inhibitors and their practical management. Br J Dermatol. 2017;177:47-62.

45. Papp KA, Bachelez H, Blauvelt A, Winthrop KL, Romiti R, Ohtsuki $\mathrm{M}$, et al. Infections from seven clinical trials of ixekizumab, an anti-interleukin-17A monoclonal antibody, in patients with moderate-to-severe psoriasis. Br J Dermatol. 2017;177:1537-51.

46. Winthrop KL, Novosad SA, Baddley JW, Calabrese L, Chiller $\mathrm{T}$, Polgreen $\mathrm{P}$, et al. Opportunistic infections and biologic therapies in immune-mediated inflammatory diseases: consensus 
recommendations for infection reporting during clinical trials and postmarketing surveillance. Ann Rheum Dis. 2015;74:2107-16.

47. Beck LA, Thaçi D, Hamilton JD, Graham NM, Bieber T, Rocklin $\mathrm{R}$, et al. Dupilumab treatment in adults with moderate-to-severe atopic dermatitis. N Engl J Med. 2014;371:130-9.

48. Thaçi D, Simpson EL, Beck LA, Bieber T, Blauvelt A, Papp K, et al. Efficacy and safety of dupilumab in adults with moderate-tosevere atopic dermatitis inadequately controlled by topical treatments: a randomised, placebo-controlled, dose-ranging phase $2 \mathrm{~b}$ trial. Lancet. 2016;387:40-52.

49. Blauvelt A, de Bruin-Weller M, Gooderham M, Cather JC, Weisman J, Pariser D, et al. Long-term management of moderateto-severe atopic dermatitis with dupilumab and concomitant topical corticosteroids (LIBERTY AD CHRONOS): a 1-year, randomised, double-blinded, placebo-controlled, phase 3 trial. Lancet. 2017;389:2287-303.

50. Blauvelt A, Simpson EL, Tyring SK, Purcell LA, Shumel B, Petro $\mathrm{CD}$, et al. Dupilumab does not affect correlates of vaccine-induced immunity: a randomized, placebo-controlled trial in adults with moderate-to-severe atopic dermatitis. J Am Acad Dermatol. 2019;80:158-67.e1.

51. Simpson EL, Bieber T, Guttman-Yassky E, Beck LA, Blauvelt A, Cork MJ, et al. Two phase 3 trials of dupilumab versus placebo in atopic dermatitis. N Engl J Med. 2016;375:2335-48.

52. de Bruin-Weller M, Thaçi D, Smith CH, Reich K, Cork MJ, Radin A, et al. Dupilumab with concomitant topical corticosteroid treatment in adults with atopic dermatitis with an inadequate response or intolerance to ciclosporin A or when this treatment is medically inadvisable: a placebo-controlled, randomized phase III clinical trial (LIBERTY AD CAFÉ). Br J Dermatol. 2018;178:1083-101.

53. Wenzel S, Ford L, Pearlman D, Spector S, Sher L, Skobieranda $\mathrm{F}$, et al. Dupilumab in persistent asthma with elevated eosinophil levels. N Engl J Med. 2013;368:2455-66.

54. US FDA. 2000. http://www.accessdata.fda.gov/drugsatfda_docs/ nda/2000/50777_Protopic_Medr_P2.pdf. Accessed 10 Mar 2019.

55. Myles IA, Williams KW, Reckhow JD, Jammeh ML, Pincus NB, Sastlalla I, et al. Transplantation of human skin microbiota in models of atopic dermatitis. JCI Insight. 2016;1:e86955.

56. Kim BE, Leung DYM. Significance of skin barrier dysfunction in atopic dermatitis. Allergy Asthma Immunol Res. 2018;10:207-15.

57. Callewaert C, Knight R, Nakatsuji T, Kosciolek T, Vrbanac A, Kotol P, et al. Dupilumab-mediated IL-4Ra blockade decreases Staphylococcus aureus colonization and increases microbial diversity in patients with atopic dermatitis [Abstract LB1505]. J Investig Dermatol. 2018;138:B7.

58. Yu S, Drucker AM, Lebwohl M, Silverberg JI. A systematic review of the safety and efficacy of systemic corticosteroids in atopic dermatitis. J Am Acad Dermatol. 2018;78:733-40.

59. Haeck IM, Knol MJ, Ten Berge O, van Velsen SG, de BruinWeller MS, Bruijnzeel-Koomen CA. Enteric-coated mycophenolate sodium versus cyclosporin A as long-term treatment in adult patients with severe atopic dermatitis: a randomized controlled trial. J Am Acad Dermatol. 2011;64:1074-84.

60. Védie A-L, Ezzedine K, Amazan E, Boralevi F, Milpied B, Taïeb $A$, et al. Long-term use of systemic treatments for moderate-tosevere atopic dermatitis in adults: a monocentric retrospective study. Acta Derm Venereol. 2016;96:802-6.

61. Schram ME, Roekevisch E, Leeflang MM, Bos JD, Schmitt J, Spuls PI. A randomized trial of methotrexate vs azathioprine for severe atopic eczema. J Allergy Clin Immunol. 2011;128:353-9.
62. Bissonnette R. JAK inhibitors appear to have a bright future in the treatment of atopic dermatitis. Br J Dermatol. 2018;178:321.

63. Drucker AM, Eyerich K, de Bruin-Weller MS, Thyssen JP, Spuls PI, Irvine AD, et al. Use of systemic corticosteroids for atopic dermatitis: International Eczema Council consensus statement. Br J Dermatol. 2018;178:768-75.

64. Moreno AS, McPhee R, Arruda LK, Howell MD. Targeting the T helper 2 inflammatory axis in atopic dermatitis. Int Arch Allergy Immunol. 2016;171:71-80.

65. Landolina N, Levi-Schaffer F. Monoclonal antibodies: the new magic bullets for allergy: IUPHAR Review 17. Br J Pharmacol. 2016;173:793-803.

66. Navarini AA, French LE, Hofbauer GF. Interrupting IL-6-receptor signaling improves atopic dermatitis but associates with bacterial superinfection. J Allergy Clin Immunol. 2011;128:1128-30.

67. Anthony RM, Rutitzky LI, Urban JF Jr, Stadecker MJ, Gause WC. Protective mechanisms in helminth infection. Nat Rev Immunol. 2007;7:975-87.

68. Ishikawa N, Goyal PK, Mahida YR, Li KF, Wakelin D. Early cytokine responses during intestinal parasitic infections. Immunology. 1998;93:257-63.

69. Wynn TA. IL-13 effector functions. Annu Rev Immunol. 2003;21:425-56.

70. Wynn TA. Type 2 cytokines: mechanisms and therapeutic strategies. Nat Rev Immunol. 2015;15:271-82.

71. Elftman MD, Hunzeker JT, Melinger JC, Bonneau RH, Norbury CC, Truckenmiller ME. Stress-induced glucocorticoids at the earliest stages of herpes simplex virus-1 infection suppress subsequent antiviral immunity, implicating impaired dendritic cell function. J Immunol. 2010;184:1867-75.

72. Chida Y, Mao X. Does psychosocial stress predict symptomatic herpes simplex virus recurrence? A meta-analytic investigation on prospective studies. Brain Behav Immun. 2009;23:917-25.

73. Ludema C, Cole SR, Poole C, Smith JS, Schoenbach VJ, Wilhelmus KR. Association between unprotected ultraviolet radiation exposure and recurrence of ocular herpes simplex virus. Am J Epidemiol. 2014;179:208-15.

74. Akinlade B, Guttman-Yassky E, de Bruin-Weller M, Simpson EL, Blauvelt A, Cork MJ, et al. Conjunctivitis in dupilumab clinical trials. Br J Dermatol. 2019. https://doi.org/10.1111/bjd.17869 (Epub ahead of print).

75. Ou Z, Chen C, Chen A, Yang Y, Zhou W. Adverse events of dupilumab in adults with moderate-to-severe atopic dermatitis: a meta-analysis. Int Immunopharmacol. 2018;54:303-10.

76. Fleming P, Drucker AM. Risk of infection in patients with atopic dermatitis treated with dupilumab: a meta-analysis of randomized controlled trials. J Am Acad Dermatol. 2018;78:62-9.

77. Gazzinelli-Guimaraes PH, Nutman TB. Helminth parasites and immune regulation. F1000Res. 2018. https://doi.org/10.12688/ f1000research.15596.1 (faculty rev 1685).

78. Maizels RM, Hewitson JP, Smith KA. Susceptibility and immunity to helminth parasites. Curr Opin Immunol. 2012;24:459-66.

79. Gonzalez ME, Schaffer JV, Orlow SJ, Gao Z, Li H, Alekseyenko $\mathrm{AV}$, et al. Cutaneous microbiome effects of fluticasone proprionate cream and adjunctive bleach baths in childhood atopic dermatitis. J Am Acad Dermatol. 2016;75:481-93.

80. Wong VK, Della Croce C, Schonfeld S, Mastrangelo AM, Lebwohl M. Use and abuse of topical corticosteroids in infections of the skin and related structures. J Drugs Dermatol. 2003;2:268-76. 


\section{Affiliations}

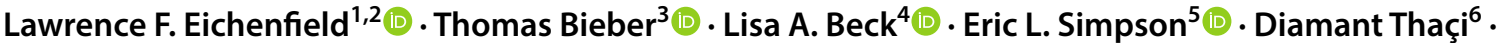

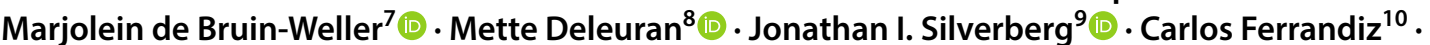 \\ Regina Fölster-Holst ${ }^{11}$. Zhen Chen ${ }^{12}$. Neil M. H. Graham ${ }^{12}$. Gianluca Pirozzi ${ }^{13}$. Bolanle Akinlade ${ }^{12}$ (1) George D. Yancopoulos ${ }^{12} \cdot$ Marius Ardeleanu $^{12}$ (1)}

1 Departments of Dermatology and Pediatrics, University of California, San Diego, San Diego, CA 92123, USA

2 Division of Pediatric and Adolescent Dermatology, Rady Children's Hospital, 3020 Children's Way, Mail Code 5092, San Diego, CA 92123, USA

3 Department of Dermatology and Allergy, Christine Kühne-Center for Allergy Research and Education, University of Bonn, Bonn, Germany

4 Department of Dermatology, University of Rochester Medical Center, Rochester, NY, USA

5 Department of Dermatology, Oregon Health and Science University, Portland, OR, USA

6 Comprehensive Center for Inflammation Medicine, University Hospital Schleswig-Holstein, Campus Lübeck, Lübeck, Germany
7 University Medical Center Utrecht, Utrecht, The Netherlands

8 Department of Dermatology, Aarhus University Hospital, Aarhus, Denmark

9 Northwestern University Feinberg School of Medicine, Chicago, IL, USA

10 Servicio de Dermatología, Hospital Universitario Germans Trias i Pujol, Badalona Universidad Autónoma de Barcelona, Barcelona, Spain

11 University Hospital Schleswig-Holstein, Dermatology, Campus Kiel, Kiel, Germany

12 Regeneron Pharmaceuticals, Inc., Tarrytown, NY, USA

13 Sanofi, Bridgewater, NJ, USA 